\title{
Odontogenic cysts- A clinicopathological study of 120 cases
}

\author{
${ }^{1}$ Dr H RaviKumar, ${ }^{2}$ Dr Ravishankar M N, ${ }^{3}$ Dr Shashikaran H C, ${ }^{4}$ Dr Reeta Jain \\ ${ }^{I}$ Professor and Head, Department of Oral Surgery Triveni Institute of Dental Sciences \& hospital Bilaspur, \\ Chattisgarh \\ ${ }^{2}$ Principal and Head, Department of oral surgery Purvanchal Institute of dental sciences GIDA, Gorakhpur \\ (U.P) \\ ${ }^{3}$ Reader, Department of Periodontics RKDF Dental College \& Hospital Bhopal \\ ${ }^{4}$ Principal and Head, Department of Prosthodntics Eklavya Dental College \& Hospital Kotputli, Jaipur, \\ Rajasthan
}

\begin{abstract}
Odontgenic cysts are pathological lesions originating from tooth forming structures and they deserve critical attention due to the complications they cause. We report a study of 120 cases of dontogenic cysts with the features recorded as age, sex, site, etiology, incidence, radiological features and histological features for confirmative diagnosis.
\end{abstract}

Key words: Odontogenic cysts, developmental cysts, inflammatory cysts.

\section{Introduction}

A cyst is a pathological cavity lined by epithelium filled with fluid, semi-fluid and gaseous material which in turn is lined by capsule of connective tissue. Odontogenic cysts are pathologies originating from the tooth forming apparatus. They grow slowly and do not cause significant clinical symptoms. Since they grow within the bones they cause tooth or bone resorption, bone expansion, fracture or tooth displacement ${ }^{1}$. It is considered that cystic proliferation and degeneration of epithelium lead to the development of odontogenic cysts. These cysts are divided into two main categories: developmental and inflammatory. Developmental cysts are of unknown origin, and do not appear from inflammatory process, while inflammatory cysts are associated with inflammation ${ }^{2}$. Apart from this World Health Organization (WHO) has classified epithelial cysts as odontogenic cysts (inflammatory and developmental) and non-odontogenic cysts (nasopalatine and nasoalveolar). Cysts without epithelial lining (pseudocysts) are non-neoplastic bone lesions which includes solitary bone cyst and aneurismal bone cyst ${ }^{3}$. We present a study performed on 120 cases that were diagnosed with different types of odontogenic cysts.

\section{Study design}

The study was conducted in the department of Oral Surgery at Bapuji Dental College, Davangere, Karnataka. A total number of 120 cases were examined, diagnosed, treated and followed up over a period of 3 years (2009-2012). The features recorded were age, sex, site, etiology, incidence, radiological features and histopathological features for the confirmed diagnosis.

Out of 120 cases, 80 were male and 40 were female. An attempt was made to categorize the etiological factors like trauma, attrition, abrasion and caries. Each jaw was divided into 4 zones namely incisor-canine, premolar, premolar-molar and molar region. Ramus and angle area were included for mandibular molar region. Radiographical analysis was done by performing periapical, occlusal, paranasal sinus and panoramic radiographs. A fine needle aspiration biopsy was performed in cases with definite clinical and radiological features.

The treatment plan for small cysts consisted of enucleation followed by primary closure, while for larger cysts marsupialization was done to facilitate decompression followed by enucleation. All the tissues were sent for histopathological diagnosis in department of oral pathology for confirmation. The follow-up was done with clinical and radiological investigations. An clinical examination was done to evaluate symptoms like pain, swelling, discoloration and loosening of teeth. Pathological findings like infection related to surgery and recurrence of cysts were assessed objectively. Healing of bony defect was assessed by post operative radiographs.

\section{Results}

The present study consisted of 120 cases with 80 males and 40 females. The age of the patients varied from 10-57 years with 48 cases in the age group of 21-30 years. Among 120 cases, the site of involvement of cyst was maxilla in 76 cases $(63.3 \%)$ and mandible in 44 cases (36.7\%). The incisor-canine area was the major site of involvement in maxilla (50\%) followed by premolar region in 2 cases $(6.7 \%)$ and one each in premolar- 
molar and molar region. In mandible molar-angle-ramus area was affected in 16 cases (13.4\%), incisor canine and premolar area were equally affected in 12 cases each and in 4 cases premolar-molar area was involved.

The type of cysts observed in the study were radicular cyst found in 60 cases (40 males and 20 females) followed by dentigerous cyst in 40 cases ( 28 males and 12 females), residual and keratocyst in 8 cases each and 4 cases of golin's cyst with equal gender distribution. The incidence of radicular cyst was $50 \%$ followed by dentigerous cyst which was $33.3 \%$, while the incidence of residual and keratocyst was $6.7 \%$ and of gorlin's cyst was 3.3\%. Among these cases 44 cases of radicular cyst occurred in the maxilla and 16 occurred in the mandible. Dentigerous cyst was equal in both jaws while residual and gorlin's cyst were seen in maxilla and keratocyst were seen in mandible.

The method of treatment was enucleation with primary closure in 76 cases, enucleation with open packing in 32 cases while 12 cases were treated with marsupialization followed by enucleation with open packing. Hundred cases were done under local anaesthesia and 20 cases were done under general anaesthesia.

\section{Discussion}

The radicular cyst is a chronic inflammatory lesion with a cavity lined by a non-keratinized stratified squamous epithelium. It is the most frequent cyst found in the jaw ranging from $38 \%-68 \%{ }^{4}$ which is consistent with our study as the frequency of radicular cyst in our study was $60 \%$. It is said to arise from the epithelial remnants in the periodontal ligament as a result of inflammation. Usually it is asymptomatic and is discovered during radiological analysis as a round or pear shaped unilocular radiolucent lesion surrounded by thin radiopaque mrgin extending from lamina dura of the involved tooth and may displace adjacent teeth or cause mild root resorption ${ }^{5,6}$. Although the source of epithelium is usually a cell rest of Malassez but other sources like crevicular epithelium, sinus lining or epithelium lining of fistulous tracts have also been considered ${ }^{7}$. Recently the role of VEGF (Vascular Endothelial Growth Factor) and MMP-9 have been suggested in the angiogenesis of radicular cyst ${ }^{8}$. It occurs commonly in males involving maxillary region in the $3^{\text {rd }}$ to $5^{\text {th }}$ decade of life which is same in our study as the incidence of radicular cyst have found to be 44 cases in the maxilla and 16 in the mandible.

Dentigerous cysts are odontgenic developmental cysts which generally occurs solitary or unilaterally commonly associated with mandibular $3^{\text {rd }}$ molars, maxillary canine, mandibular $2^{\text {nd }}$ premolar and maxillary $3^{\text {rd }}$ molars9. They occur commonly in adolescents and young adults and often involve mandibular molars; which is consistent with our study as the age of the patients varied from 21-30 years. The exact etiopathogenesis of dentigerous cyst is unknown but it has been proposed that the crown of a permanent tooth may erupt into a radicular cyst of a primary predecessor resulting in the formation $\mathrm{f}$ an extra follicular dentigerous cyst. This theory was rarely accepted because radicular cyst involving primary dentition is extremely rare ${ }^{10}$. There are no characteristic histopathological features which can be used reliably to distinguish the dentigerous cyst from other types of odontogenic cysts. It is usually composed of thin connective tissue wall with a thin layer of stratified squamous epithelium lining the lumen ${ }^{11}$.

Odontogenic keratocyst $(\mathrm{OKC})$ is a benign intraosseus odontogenic tumor occurring from first to ninth decade of life with males commonly affected than females. The mandible is involved more than the maxilla ${ }^{12}$ which is same in our study also. It involves approximately $10 \%$ of all jaw cyst with predominance in molarangle-ramus are $^{13}$ which is consistent with the area involved in our study also. On clinical examination OKC presents itself as swelling, pain, discharge, aggressive growth, invasion of adjacent structures, recurrence and localized asymptomatic swelling which is the most common symptom ${ }^{14}$. In our study the patients were found only with the clinical symptom of swelling and pain. Radiographically OKC shows unilocular or multilocular radiolucency with scalloped and well defined margins which is same as the radiographic details in our study also.

The calcifying cystic odontogenic tumor or Gorlin's cyst was first described by Gorlin in 1962 and it was recognized as a distinct pathologic entity by WHO in 1971. It is a benign cystic neoplasia constituting $2 \%$ of benign odontogenic lesions and representing $1 \%$ of odontogenic cysts ${ }^{15}$ which is consistent with our cases also (4 Cases). It is divided into 3 subgroups based on location (intraosseous and extraosseous) and histologic features ${ }^{16}$. It shows ameloblastoma like ghost cells that may calcify and has been shown to have diversity in its clinical and histologic features. Clinically, it presents as a painless slow growing tumor, equally affecting maxilla and mandible involving most commonly the incisor-canine area. It occurs in third to fourth decade of life with no gender predilection ${ }^{17}$ which correlates with our study also. The characteristic features of Gorlin's cyst is the presence of ghost cells which are also found in other tumors like Malherbe calcificant epithelioma of skin, ameloblastic fibro-odontoma, complex and compound odontoma, craniofaringioma, meloblastoma and carcinoma which should be excluded while reporting Gorlin's cyst. Since the nature of the ghost cells is unknown, the accepted theory states that there would be a squamous metaplasia of the epithelium with the subsequent queratinization which could be normal or aberrant. 
It is concluded that association of different types of odontogenic cysts with the age, sex, site, etiology, incidence and histopathological features reveals that demographic knowledge can be helpful in early diagnosis and their prompt treatment.

\section{References: -}

[1]. Manal A and Sheddi Al. Odontogenic cysts- A clinicopathological study. Saudi Med J 2012; 33(3): $304-308$

[2]. Avelar RL, Antones AA, Carvalho R W F, Bezerra Paulo G C F, Neto P J O and Andrade E S S. odontogenic cysts- A clinicopathological study of 507 cases. Journal of Oral Science 2009; 51(4): 581-586.

[3]. Monteiro L, Lapena J D, Fonseca L, Paiva A and Amaral B D. Odontogenic cysts- A descriptive pathological study. Braz J Oral Sci 2005; 4(12): 670-675.

[4]. Pekiner F N, Borahan O, Ugurlu F, Horasan S, Sener B C and Olgac V. Clinical and radiological features of a large radicular cyst involving the entire maxillary sinus. MUSBED 2012; 2(1): 31-36.

[5]. Toomarian L, Moshref M, Mirkarimi M, Lofti A and Beheshti M. Radicular cyst associated with a primary first molar: A case report. Journal of Dentistry, Tehran University of Medical Sciences, Tehran, Iran 2011; 8(4): 213-217.

[6]. Holla V A, Chatra L, Shenai P, Rao P K, Veena K M and Prabhu R V. Bilateral inflammatory cysts of the jaw: Report of an unusual case. Imaging Science in Dentistry 2012; 42: 105-9

[7]. Amos M J, Dalghous A, Alkhabuli J and MIzan K D. Massive maxillary radicular cyst presenting as a facial fracture and abscess, A case report. Libyan J Med; AOP 070922: 211-213.

[8]. Pavaskar R, Gera T, Boyapati C M, Chalakkal P and Bommannavar S. Radicular cyst with severe destruction of the buccal cortical plate secondary to endodontic failure. Journal of Clinical and Diagnostic Research 2013; 7(8): 1816-1817.

[9]. Freitas D Q, Tempest L M, Sicoli E and Lopes-Neto F C. Bilateral dentigerous cysts: Review of literature and report of an unusual case . Dentomaxillofacial Radiology 2006; 35: 464-468.

[10]. Nagaveni N B, Umashankara K V and Radhika N B. Inflammatory dentigerous cyst associated with an endodontically treated primary second molar: A case report. Archieves of orofacial sciences 2011; 6(1): 27-31.

[11]. Rajendran R and Sivapathsundharam B. Shafer's textbook of oral pathology $2009 ; 6^{\text {th }}$ edition: $254-256$.

[12]. Asokan G S, Jeelani S, Pratibhan J, Prabhu S K, Prakash C A and Shankar K A. Keratocystic odontogenic tumor- A case report and review of literature. Int J Dent Case Reports 2012; 2(1):87-91.

[13]. Bland P S, Shiloah J and Rosebush M S. Odontogenic keratocyst: A case report and review of an old lesion with new classification. Journal of the Tennessee Dental Association 2012; 42: 33-38.

[14]. Cakur B, Miloglu O, Yolcu U and Goregen M and Gursan N. Keratocystic odontogenic tumor invading the right maxillary sinus: A case report. Journal of Oral Science 2008; 50(3): 345-349.

[15]. Periera C M, Carneiro D S, Pofahl H B C, Gasparetto P F and Silvajunior A F. calcifying cystic odontogenic tumor radiographically mimicking a lateral periodontal cyst: Clinical case report. J Health Sci Inst. 2010; 28(4): 315-7.

[16]. Cazal C, Sobral A P V, DaSilva V C R and deAraujo. Extraosseous calcifying odontogenic cyst: A case report and a literature review. J Bras Patol Med Lab 2005; 41(6): 443-6.

[17]. Cury S E. Calcifying cystic odontogenic tumor- A case report. Webmedcentral Oral Medicine 2011; 2(12): 1-7. 